\title{
Design and Analysis of an Online Course using Moodle Platform
}

\author{
Prapulla S B ${ }^{1}$, Jyoti Shetty ${ }^{2}$, Vinay A Kulkarni ${ }^{3}$, K N Subramanya ${ }^{4}$, . Uma B V ${ }^{5}$, .Ramakanth \\ Kumar $\mathbf{P}^{\mathbf{6}}$, Dr.Shobha $\mathbf{G}^{7}$
}

${ }_{1,2,4,5,6,7}$ R.V College of Engineering, Bengaluru, India

${ }^{3}$ DY Patil college of Engineering, Akurdi, Pune

\begin{abstract}
The components of Technological (T) Pedagogical (PA) Content (C) Knowledge (K) (TPACK) needs to be effectively integrated and disseminated for achieving Knowledge, Assimilation and Reflection of learner's learning. A case study of learners responses in Digital Logic Design course is demonstrated in this paper by following an integrated approach of $\mathrm{LeD}, \mathrm{LbD}$ and RCA. It is found that learners ability to achieve Higher Order Thinking Skills (HOTs) is enhanced upto $61.57 \%$.
\end{abstract}

Keywords: TPACK, Teaching-Learning Process (TLP), Information and Communication Technology(ICT).

\section{Introduction}

Information and communication technologies (ICTs) are the innovations utilized in conveying, control and management of information by electronic methods. Using a flipped classroom with an active learning strategy has led to effective teaching(Prince, M., 2004)(Kothiyal et. al,2013)). Employing various ICT tools promote learning and enhance skills. Plickers (plickers 2019) is a tool that lets you poll your class for free, without the need for learner devices. This tool could be used to take instant feedback say about the understanding of the concepts taught in the class.

To produce good quality learning using ICT, learners should develop technological and learning competencies, and teachers should develop teaching, learning, professional, and technological competencies to improve learning outcomes. It is believed that this can help learners become lifelong learners. These competencies must be explicit for teachers and learners to improve the Teaching-Learning Process (TLP) and at the same time be able to evaluate them.

Technological Pedagogical and Content Knowledge(TPACK)(Schmidt DA, 2009) system shows a perspective about the incorporation of innovation, specific learning related to coordinating innovation adequately into learning situations. TPACK has the guarantee to shape the way teachers and expert designers plan educators to incorporate innovations.

According to Koehler TPACK[4] framework builds on Lee Shulman's construct of Pedagogical Content Knowledge(PCK) to include technology knowledge Technological Knowledge - it is the knowledge of technology use e.g, knowledge of designing a Wordpress site.P- Pedagogical Knowledge - It is the knowledge of delivering lectures effectively e.g., classroom management skills.C- Content Knowledge - It is the subject domain knowledge of a teacher. PCK - It is the knowledge of how effectively the teacher teaches a subject using pedagogical strategies. TCK - It is the knowledge of how effectively the teacher teaches a subject using technology. TPK- It is the knowledge of how effectively the teacher implements pedagogical strategies using technology.

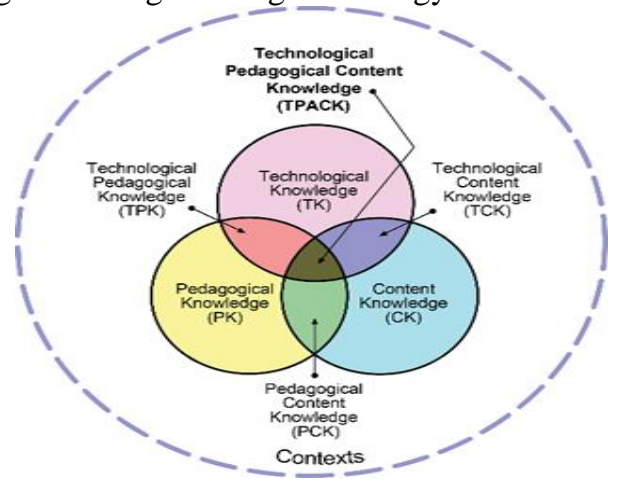

Fig. 1 TPACK model[2]

TPACK- Technological Pedagogical Content Knowledge- It is the integration of knowledge of technology, content, and pedagogy.

The contributions of this work are as follows:

i. Demonstration of Blended learning in Teaching Learning and Evaluation by partial delivery of a course using an online Moodle platform.

ii. Analysis of learner perception of engagement, learning and usability

Outcome of this activity:

Active participation of learners motivated the course creators to inculcate blended learning for other courses as it permits pervasive learning for learner community.

\section{TPACK Components of an Online Course}

This section will discuss the components of the online course on Digital Logic Design from the TPACK perspective.

A. Technology knowledge component 
This knowledge deals with the technical ability to create an online course using platforms such as Moodle. There are various free and commercial Moodle platforms available for hosting online courses. Some of the free platforms for creating online courses are gnomio.com, Moodlecloud.com, canvas.com and so on. These platforms also have paid versions with more features and resources. They are very simple and user-friendly, require no coding or much technical knowledge. However, it requires a user to explore and learn to build own courses. There are many resources available on the web which can guide the course creation. The proposed course is built using the free version of the gnomio.com platform.

\section{B. The pedagogical knowledge component}

Pedagogical knowledge deals with the creative delivery of the course effectively. For instance, say to teach programming language, the teacher may demonstrate the execution of programs in the class. Depending on the course, the pedagogy used by the instructor varies widely. For the proposed online course the pedagogical knowledge used are as follows (Warriem, J. M., 2014)(Warriem, J. M., 2015):

Learning Dialogues (LeDs): are the video resources used for delivering the information to the learners. The videos can be created by the course teacher or existing educational videos with Creative Commons license can be used. The course creator can mandate the learners to perform any activity such as watching an LeD, taking a quiz etc before proceeding to next activity using the 'Restricted Access' option of Moodle. Mere video watching will be a passive activity, hence a pedagogical modification would be to introduce a "Reflection Spot", wherein the presenter would pose a question to the learner based on the video content and take a pause asking a question to the user over the delivered content, the user is expected to think and write answers. The Reflection Spot questions posed should be of lower cognitive level. In the discussed Digital Logic Design course a question is posed in the video after explaining the concept about the conversion of flipflops, Question: the characteristic table is written for which flip flop? Where learners have to write down the answer.

Learning by Doing Activities (LbDs): are the questions or problems to be attempted by the learners after completion of watching videos. It is similar to a teacher asking questions to learners after completing the lesson in a physical classroom. LbDs helps learners to acknowledge their understanding of the concepts. In the discussed Digital Logic Design course 2 to $3 \mathrm{LbDs}$ are included for each LeD. Sample Questions include: What is/are the crucial function/s of memory elements used in the sequential circuits?

Learning Extension Resources (LxTs)s: This component includes additional resource materials on the topic to support extended learning. In a classroom there will be learners with different learning quest, LxTs serve the purpose of providing additional resources to advanced learners.
In the proposed course five resources are shared as LxTs: Applications of Flip Flops, Sequential Circuit Notes, and other related material.

Learning Experience Interactions (LxIs): This component is all about interaction among the learners virtually on forums like group discussion chats in Moodle or a Whatsapp group. This encourages collaborative learning among peers.

In the proposed course, a group discussion forum is setup where the learners discussed the advantages of Flip Flops, JK Flip Flops, MS Flip Flops. There are 6 threads on various topics and about 40 messages were exchanged. To encourage and instigate discussion the course instructor has posed a few questions for learners to answer and discuss. Further, the course instructor provides feedback to the answers given by the learners, so that learners feel they are attended by the instructor just like in a physical classroom.

Knowledge Quizzes (KQ): These are the graded quizzes based on the course content. Graded activities show the involvement of learners and acquisition of knowledge. Knowledge quizzes cater to apply the acquired knowledge to real time problem solving. The objective of KQ is to reflect the understanding of the basic content of the course and apply that knowledge to application/create/construct type of questions. The Moodle platform supports various types of questions like multiple choice, match the following, fill in the blanks, numerical, essay, true or false, drag and drop image, drag and drop text and many more. With numerical questions, it is possible to randomize the values such that the vales will be different for every learner. It has provision to track the learner engagement i.e., how much time a learner spends on the activities.

In the proposed course 12 questions were asked in KQ with a variety of question types discussed above. Sample Knowledge Quiz question: Construct a JK flip-flop using a D Flip-flop, a 2-to-1 line multiplexer, and an inverter.

Resource Creation Assignment (RCA): These are the assignments that include assignments at a higher level of Bloom's taxonomy analysis, synthesis or evaluation (Anderson, Lorin, 2001).

In the proposed course an RCA to design a circuit was given as an assignment. The assignment was to build a sprinkler system using decoders and microcontrollers. Learners have to specify the number of components required for optimal design and also justify their design.

Reflection quiz (RQ): Interaction is important for learning. The RQ objective is to engage learners interaction in the forum. It includes questions of a lower cognitive level based on the discussion forum.

In the proposed course there are three Reflection Quiz questions. Sample Reflection Quiz question: Unlike D flip flops and SR latches, JK flip flops have the useful property of toggling when both data inputs are logic 1 . Who has answered this?

Assimilation Quiz (AQ): This quiz is based on LxTs. The AQ quiz questions are confined to the extra resources provided. There are 5 AQs in the proposed course. Sample AQ includes 


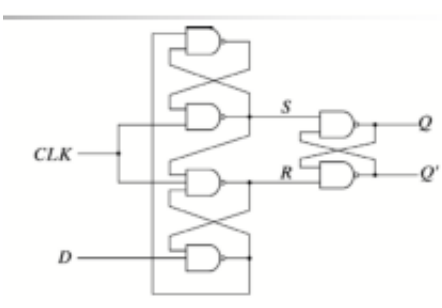

Fig.2 positive edge-triggered D Flip-flop

The above Fig.2 shows the positive edge-triggered D Flipflop, analyze the output of the S'R' latch (Q) when the clock has become 1 and $\mathrm{D}=0$.

C. The content knowledge component

This knowledge deals with the course content knowledge e.g. Digital logic design, Operating systems, etc. The proposed online course is on Digital Logic Design.

\section{Analysis of Course}

An online course on Digital Logic Design for 2nd year engineering graduates is designed and offered. More than 100 participants had registered and successfully completed the course as part of the blended teaching-learning process. Following analysis are carried out on the course.

\section{A. Analysis of engagement:}

The analysis of engagement is about the involvement of learners in the course based on their participation in various activities in the course. The activity completion report produced from the Course Report section demonstrates the commitment of learners in the exercises as shown in Table 1.

Table 1: Activity Completion Summary

\begin{tabular}{|c|c|c|}
\hline \multicolumn{2}{|c|}{ Activity } & \multirow{2}{*}{$\begin{array}{c}\begin{array}{c}\text { Completion } \\
\text { Status }\end{array} \\
62\end{array}$} \\
\hline \multirow[t]{5}{*}{ LeDs } & 1 & \\
\hline & 2 & 62 \\
\hline & 3 & 62 \\
\hline & 4 & 62 \\
\hline & 5 & 62 \\
\hline \multirow[t]{5}{*}{ LbDs } & 1 & 62 \\
\hline & 2 & 53 \\
\hline & 3 & 42 \\
\hline & 4 & 38 \\
\hline & 5 & 36 \\
\hline
\end{tabular}

\begin{tabular}{|c|c|}
\hline $\begin{array}{c}\text { Discussion on } \\
\text { Flip Flops }\end{array}$ & 40 \\
\hline RQ & 61 \\
\hline LxTs & 65 \\
\hline AQ & 128 \\
\hline KQ & 58 \\
\hline
\end{tabular}

B. Analysis of learning

Analysis of the learning of the learners is done by examining the marks secured by the learners in various quizzes and activities. There were four types of quizzes and one activity for the participants. Table 2 below depicts the marks scored by the learners in each of the activity. The weightage considered for each of them is given below. Learning by Doing (LbD) Activities-[Ungraded], Reflection Quiz - [10\%], Assimilation Quiz - [20\%], Knowledge Quiz [50\%], Resource Creation Assignment - [20\%]. As multiple tries were permitted for ungraded activities, learner engagement was slightly more compared to graded quizzes like KQ as they need not bother about marks/ grades.

Table 2: Number of participants who attempted each activity and the average, marks and percentage they scored

\begin{tabular}{|l|l|l|l|l|}
\hline & $\begin{array}{l}\text { LbDs } \\
\text { (ungraded) }\end{array}$ & RQ & AQ & KQ \\
\hline $\begin{array}{l}\text { No of } \\
\text { persons } \\
\text { attempted }\end{array}$ & 62 & 61 & 128 & 58 \\
\hline $\begin{array}{l}\text { Average } \\
\text { Marks }\end{array}$ & 9.4 & 7.7 & 5.787 & 6.15 \\
\hline $\begin{array}{l}\text { Maximum } \\
\text { Marks }\end{array}$ & 10 & 10 & 10 & 8.33 \\
\hline $\begin{array}{l}\text { Average } \\
\text { Percentage }\end{array}$ & 86.84 & 77.05 & 57.66 & 61.57 \\
\hline
\end{tabular}

C. Analysis of perception

The analysis of the overall perception of learners is done through the three feedback surveys-Perception of Learning, Perception of Engagement, and Perception of Usability. The survey questions and the feedback responses are as shown in the graph in Fig.3. 


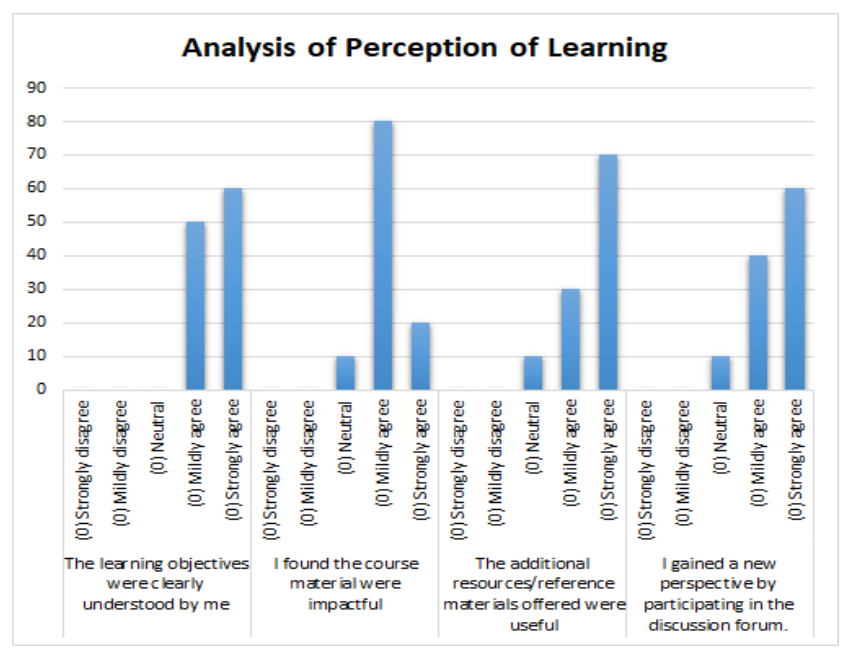

Fig. 3 Perception of Learning

From the perception of learning feedback, it is observed that the participants had a good learning experience offered by the course. Talking about the learning avenue offered by additional resources/reference materials, learners are strongly agreeing about their learning potential. This suggests that the materials provided gave in-depth knowledge of the topic.

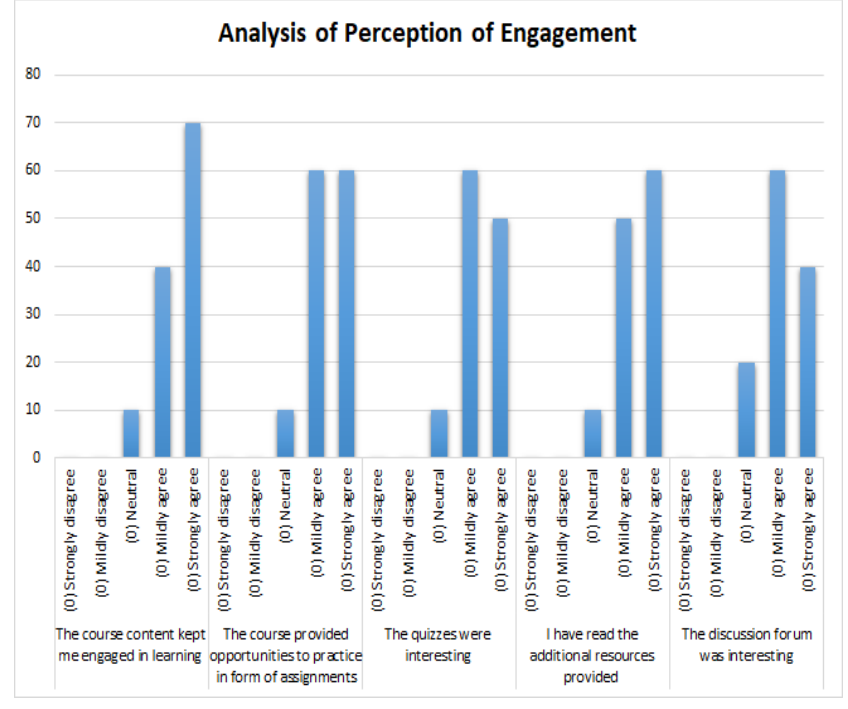

Fig. 4. Perception of Engagement

It is evident from the graph in Fig. 4, that the perception of engagement has been high. Observing each criterion, it is seen that the participants are actively involved each time they access the course and find the additional resources/reference materials engaging enough. Also it is seen that though the opinion about the engagement is diverse, a good number of learners find the quizzes mildly engaging.

From the graph in Fig. 5, the four categories used to evaluate the usability of the course helps in arriving at the following conclusions. Most of the participants mildly and strongly agree about the usability of the course, except for the consistency in course material and navigation between course modules, where the response is neutral and mildly disagree. Though the discussion forum was interesting but did not prove to be very impactful forum as learners are more comfortable with communication platforms like whatsapp, skype etc. The focus questions posed in the forum could have been more thought provoking.

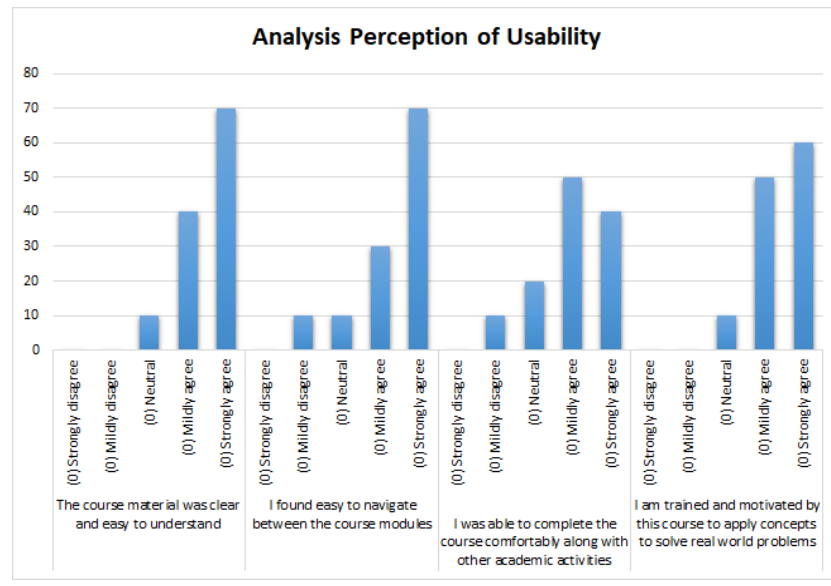

Fig. 5 Perception of Usability

4. Reflecting on engagement, learning, and perception The overall data about engagement shows that the participants are able to complete the activities/quizzes as the course progressed. Also, from the data on scores of participants, it is seen that the scores of the participants are encouraging. This indicates that the perceived learning value of the course is strongly met. From the participants analysis of the perception of learning all the participants agreed that the course objectives were clearly understood by them, so it is inferred that the course outcomes are clear and communicated well to the learners. From the analysis of the perception of Engagement more than $90 \%$ of them agree with the point that the course content kept them engaged in learning, which clearly signifies the quality of valuable information provided in the course. From the participants perception of Usability of the course, it can be observed that the ( $8 \%$ of total enrolled) navigation in the course modules and the time duration to complete course material needs some improvement.

The analysis shows that the course was engaging enough and provides the scope for improving the usability, while from scores of participants it is clearly depicted that the majority of learners have strongly agreed about the course meeting their objectives, provided impactful material / additional resources, provided opportunities for assignment learning/ quizzes, etc. and kept them trained and motivated in their lifelong learning process. This suggests that the course designed really offered in-depth knowledge of the topic.

\section{Conclusion}

Blended learning (Integrating Approach) in Teaching Learning and Evaluation, is a must for 21st Century Education. Three major components of learners learning 
(Knowledge, Accumulation and Reflection) need to be disseminated and practiced by the learners. KAR approach presented in this paper, not only improvises the learning satisfaction of learners but also learners can develop their learning in higher-order thinking skills (HOTs). The structured way of following, outcome-oriented TPACK with the integration of KAR yields more benefits as depicted in this study.

\section{REFERENCES}

Prince, M. (2004). Does active learning work? A review of the research. Journal of engineering education, 93(3), 223231

Kothiyal, A. Majumdar, A., Murthy, S. \&Iyer, S(2013) "Effect of Think-Pair-Share in a large CS1 class: 83\% sustained engagement" ACM - ICER, San Diego

https://www.plickers.com/ [accessed on 15th September 2019]

Schmidt DA, Baran E, Thompson AD, Mishra P, Koehler MJ, Shin TS(2009). Technological pedagogical content knowledge (PCK): the development and validation of an assessment instrument for pre-service teachers. Journal of Research on Technology in Education.42(2):123-149.

Warriem, J. M., Murthy, S. and Iyer, S. (2014). A2I: A Model for Teacher Training in Constructive Alignment for Use of ICT in Engineering Education, In Proceedings of 22nd International Conference on Computers in Education, Nara, Japan.

Murthy, S., Iyer, S., \&Warriem, J. (2015). ET4ET: A LargeScale Faculty Professional Development Program on Effective Integration of Educational Technology. Educational Technology \& Society, 18 (3), 16-28

Anderson, Lorin W.; Krathwohl, David R., eds. (2001). A taxonomy for learning, teaching, and assessing: A revision of Bloom's taxonomy of educational objectives. Allyn and Bacon. ISBN 978-0-8013-1903-7 